\title{
JURNALISME SASTRA: \\ LAPORAN PERISTIWA SECARA NARATIF DAN VARIATIF
}

\author{
Suhaimi \\ Dosen Fak. Ilmu Dakwah dan Ilmu Komunikasi \\ UIN Syarif Hidayatullah Jakarta
}

\begin{abstract}
:
Internet as a form of communication technology today, on the one hand has urged members of the press who worked on several major news papers to change form into smaller, but the number of pages grew thicker with a more slender appearance and full color. It is achallenge for reporters now are required to be more skilled from their elders in preparing the report journalism.

Literary journalism or narrative reporting is news writing made in narra-tive form of variety of different angles according to the facts and not fiction essay. In Indonesia literary journalism gives a place for journalists to actualize his being. Therefore, it requires a journalist to be able to create a narrative, descriptive or a detailed, lively, contextual, and relevant reports.
\end{abstract}

Key Words: newspaper, literary journalism, journalist

\begin{abstract}
Abstrak
Internet sebagai sebuah bentuk teknologi komunikasi saat ini, di satu sisi mendesak anggota pers yang bekerja pada beberapa surat kabar besar untuk memperkecil bentuk, tetapi jumlah halaman bertambah tebal dengan tampilan yang lebih ramping dan penuh warna. Ini adalah tantangan karena wartawan sekarang dituntut untuk lebih terampil mempersiapkan laporan jurnalistiknya.

Jurnalisme sastra atau laporan naratif merupakan penulisan berita dalam bentuk narasi yang dilihat dari berbagai sedut pandang sesuai dengan fakta dan bukan merupakan esai fiksi. Jurnalisme sastra Indonesia memberikan tempat bagi wartawan untuk mengaktualisasikan dirinya. Oleh karena itu, dibutuhkan wartawan yang dapat menciptakan laporan-laporan yang naratif, deskriptif, detail, menarik, kontekstual, dan relevan.
\end{abstract}

Kata Kunci: surat kabar, jurnalisme sastra, wartawan.

\section{Pendahuluan}

Kehadiran internet sejak abad ke-20 M telah mengantarkan umat manusia kepada peradaban era informasi (the information age) yang bercirikan media massa sebagai komoditas industri. Manusia kini semakin menyadari bahwa kemajuan teknologi komunikasi menjadikan informasi memiliki nilai ekonomi tinggi yang dapat diperjualbelikan.

Perkembangan teknologi komunikasi kini semakin memberdayakan manusia dengan akses data yang melimpah, melebihi apa yang mereka dapat bayangkan sebelumnya. Manusia pun mengalami transisi yang cepat dari cyberspace ke cyberchaos, dari ruang maya ke kacauan maya. Setiap saat diperlukan di dalam rumah, televisi menghadirkan kabar dan kejadian dengan begitu hangat dan hidup kepada khalayak yang disampaikan oleh para reporter yang berparas cantik. Di ruang kamar, manusia dapat 
bertamasya mengarungi dunia maya dengan kekayaan informasi yang luar biasa. Mereka mengalami ketegangan memilih antara hanyut dalam cyberporn atau cyberdemocracy, atau cyber yang lain.

Pada satu sisi, internet pun telah mendesak insan pers yang bekerja pada beberapa koran besar untuk mengubah formatnya menjadi lebih kecil, dari format broadsheet ke junior broadsheet atau compact, atau lebih kecil lagi ke format "midi", tapi jumlah halamannya bertambah tebal dengan penampilan yang lebih langsing dan penuh warna. Hal ini menjadi tantangan tersendiri bagi para wartawan sekarang yang dituntut untuk lebih terampil dari para senior mereka dalam menyusun laporan jurnalistik. Tulisan berikut ini menawarkan konsep jurnalisme sastra sebagai salah satu varian jurnalisme baru yang dapat menjadi pilihan para wartawan berkreativitas.

\section{Jurnalisme Sastra; Varian Jurnalisme Baru}

Sejak pertama lahir pada zaman Mesir Kuno dan Romawi Kuno, media massa memiliki fungsi generik memberikan informasi kepada khalayak dan sejalan dengan kemajuan teknologi komunikasi, informasi dari media massa sekarang ini dapat mewariskan peradaban baru antar generasi seperti telah digambarkan dalam pendahuluan tertulis di atas.

Harold D. Lasswell lebih lanjut menguraikan fungsi media massa dalam tulisannya "The Structure and Function of Communication in Society", selain 1) transmisi warisan sosial, dia menyatakan pula fungsi 2) pengawasan lingkungan atau kontrol sosial dan 3) interpretasi, ${ }^{1}$ kemudian fungsinya yang ke 4) hiburan.

Untuk memainkan fungsi-fungsinya seperti disebutkan di atas, setiap media massa memiliki strategi komunikasi masing-masing. Dalam hal ini media massa cetak memiliki pendekatan yang berbeda dengan media massa elektronik. Perbedaan itu terutama dapat dilihat pada strategi penyusunan pesan-pesan yang akan disampaikannya kepada khalayak.

Pada media massa elektonik seperti salah satunya bisa dilihat dalam televisi dan radio maupun online, pesan-pesan diterima khalayak hanya sekilas. Di Indonesia, televisi merupakan medium terfavorit bagi para pemasang iklan, dan karena itu mampu menarik investor untuk membangun industri televisi. Apalagi televisi saat ini telah menjadi bagian tak terpisahkan dari kehidupan banyak orang. Para pemirsa menghabiskan waktunya lebih lama di depan pesawat televisi dibandingkan dengan waktu yang digunakan untuk membaca, berdiskusi dengan keluarga atau pasangan mereka. ${ }^{2}$

Sedangkan pada media cetak, pesan-pesan yang diterima khalayak dapat dikaji ulang dan dipelajari serta disimpan untuk dibaca kembali pada setiap kesempatan dimana diperlukan. ${ }^{3}$

Di dalam media cetak terdapat beberapa gaya penelitian seperti gaya penelitian straight news, feature, dan narasi. Gaya bahasa yang dilakukan dalam straight news itu menggunakan bahasa yang informatif dengan data-data yang faktual, lugas dan akurat yang berpedoman pada rumus 5W1H (what, when, where, who, why, dan how) dengan kaidah piramida terbalik.

Sementara feature itu sendiri adalah berita atau karangan khas yang berpijak pada fakta dan data yang diperoleh melalui proses jurnalistik, dan tidak tunduk kepada kaidah pola piramida terbalik dengan rumus $5 \mathrm{~W} 1 \mathrm{H}$. Karena feature itu sendiri menggunakan bahasa yang menarik perhatian banyak pembaca dengan di bubuhi unsur human touch, yaitu sentuhan penasaran manusia.

Sejarah lahirnya Jurnalisme Sastra di awali oleh Tom Wolfe, wartawan cum novelis wartawan asal Amerika, pada 1960-an memperkenalkan genre atau gerakan ini dengan nama new journalism (jurnalisme baru). Ia memberikan batasan Jurnalisme Sastra pada tahun 1973 dalam antologi berjudul The New Journalism. Isinya kumpulan artikel-artikel 
terkemuka pada saat itu. Ia menyebut artikel-artikel itu sebagai jurnalisme baru, sedangkan para penulisnya jurnalis baru.

Pada 1973, Wolfe dan E. Johnson menerbitkan ontologi dengan judul The New Journalism. Mereka memasukkan narasi-narasi terkemuka pada zaman itu, antara lain tulisan dari Hunter S. Thompson, Joan Didion, Truman Capote, Jimmy Breslin, dan Wolfe sendiri. Mereka bilang genre ini berbeda dari reportase sehari-hari karena dalam bertutur menggunakan adegan demi adegan (scene by scene construction), reportase yang menyeluruh (immersion reporting), menggunakan sudut pandang orang ketiga (third person point of view), dan penuh dengan detail. Wawancara bisa dilakukan dengan puluhan bahkan ratusan narasumber. Risetnya tidak main-main. Waktu bekerjanya bisa berbualnbulan.

Beberapa pemikir

jurnalisme mengembangkan temuan Wolfe. Ada yang menyebut narrative reporting atau passionate journalism. Pulitzer Prize menyebutnya explorative journalism. Apapun sebutannya, genre ini menukik sangat dalam. Lebih dalam daripada apa yang disebut sebagai in-depth reporting. Laporannya panjang dan utuh tidak dipecah-pecah ke dalam beberapa laporan. ${ }^{4}$

Sejarah lahirnya jurnalisme baru menurut JB Wahyudi, jurnalistik baru dikembangkan pada tahun 1970-an oleh Paul Williams, seorang perintis laporan investigatif atau unvestigative reporting. Ia juga seorang pendiri Perkumpulan Wartawan dan Editor yang melakukan upaya pemasyarakatan laporan investigatif di Indianapolis Amerika Serikat pada tahun 1976.

Jurnalistik baru beritanya bersifat mulitilinier, tidak seperti jurnalistik lama yang bersifat linier (satu referensi saja). Artinya jurnalistik baru mengunakan referensi-refernsi pokok, yaitu kejadiannya, juga dilengkapi dengan referensi-referensi lain, seperti wawancara dengan orang yang mengetahui kejadian itu, kliping surat kabar, majalah, buku dan sebagainya. Sehingga beritanya jauh lebih lengkap daripada berita yang ditulis dengan gaya jurnalistik lama. Contohnya jika terjadi banji, maka beritanya tidak terbatas banjir itu saja, tetapi dilengkapai dengan data lain tentang peristiwa banjir ditempat itu di waktu yang lalu, seperti minggu lalu atau bulan lalu atau sekian tahun lalu di tempat tersebut pernah terjadi banjir yang sama besarnya atau malah lebih besar dari pada yang terjadi sekarang.

Jadi, jurnalistik baru menggali fakta-fakta yang tersembunyi yang kelihatan di permukaan saja. Fakta yang tersembunyi hanya bisa diketahui dengan menggali pada berbagai sumber, seperti wawancara dengan orang yang mengetahui kasus itu, berita surat kabar yang pernah ada, ulasan majalah dan buku, dan sebagainya. ${ }^{5}$

Di Indoneisa Jurnalisme Sastra memberi tempat bagi wartawan untuk mengaktualisasikan keberadaan dirinya. Sebab, ia menuntut seorang wartawan untuk mampu membuat narasi, ataupun deksripsi yang rinci, hidup, kontekstual, dan relevan. Tidak mungkin seorang wartawan hasil seminggu pelatihan hanya dengan bekal $5 \mathrm{~W}+1 \mathrm{H}$ bisa memenuhi standar karya Jurnalisme Sastra

\section{Kaidah Penulisan Jurnalisme Sastra}

Ada tiga hal yang penting di dalam Jurnalisme Sastra, yaitu :

1. Tulisannya bersifat jurnalistik, yang disuguhkan kepada pembaca. Sifat jurnalistiknya tercermin dari penggalian subyek berita yang sungguh-sungguh menerapkan asas-asas jurnalistik: berdasar peristiwa aktual, wawancara atau datang langsung ke sumber berita, jujur, mencakup sumber dua arah, dan lainnya.

2. Tak sekadar suatu laporan yang singkat dan dangkal. Yaitu berdasar pada suatu investigasi yang mendalam, yang meliputi pengamatan dan wawancara yang luas. Pada tingkat tertentu, boleh dikata, investigasi ini sudah setara untuk tidak mengatakannya 
kadang bahkan melebihi suatu penelitian sosial. Tak jarang ia diperlengkapi pula dengan studi pustaka. Membacanya kita bukan semata beroleh keping-keping informasi, tapi juga suatu pengetahuan. Kita tak sekadar mendapat kesan, tapi sungguh seperti menemu ilmu.

3. Sebagaimana adjektif yang disandang Jurnalisme Sastra dihadirkan sebagai laporan panjang atau sejenis feature yang ditulis dengan pola seperti orang bercerita. Dan memang pada dasarnya ia hendak bercerita, bukan sekadar berkabar. Lancar, mengalir, dan renyah. Tidak kaku dan berat sebagaimana bahasa ilmiah, namun juga tidak dangkal sebagaimana tulisan straight news biasa. Diksinya dipilih dengan cermat. Sebisa mungkin tidak boleh ada pengulangan kata. Kalimat-kalimat yang panjang dan bertingkat, yang membuat rumit dan berbelit, sedemikian rupa dihindari. Pembaca lalu seperti disuguhkan sebuah tulisan bergaya sastra, yang tak membosankan dan ingin terus mencicipinya.

Ketiga hal di atas setara pentingnya. Tak ada yang lebih utama dan tak ada yang lebih di belakang. Ketiganya merupakan pokok yang menyatu dan berada dalam satu tubuh yang disebut Jurnalisme Sastra itu. Kemampuan jurnalistik, penelitian sosial, dan penulisan bergaya sastra sekaligus tampaknya harus dimiliki oleh seorang pelaku Jurnalisme Sastra. ${ }^{6}$

Selain itu terdapat beberapa aturan jurnalisme sastra sbb.:

1. Riset mendalam dan melibatkan diri dengan subjek

Jurnalisme sastra membutuhkan waktu yang lama dalam melakukan reportase. Oleh sebab itu data yang ada lebih akurat dan mendalam. Selain itu para jurnalis sastra harus lebih mendekatkan diri kepada sumber agar data yang ada semakin akurat. Jurnalis juga harus mempunyai kepekaan yang tinggi terhadap perilaku sumber.

2. Jujur kepada pembaca dan sumber berita

Pembaca merupakan hakim yang tidak boleh dibohongi penulis.oleh karena itu, jurnalis harus menjaga hubungan baik dengan pembaca dan sumber berita.

a. Hubungan penulis dengan pembaca

Penulis tidak boleh dengan sengaja mengkombinasi atau memperbaiki adegan demi adegan, mengagregasi karakter, memoles kutipan, atau mengubah keaslian materi liputan mereka. Ini yang membedakan mereka dengan penulis fiksi.

b. Hubungan penulis dengan sumber berita

Ini menyangkut cara mencari dan menjaga kepercayaan narasumber terhadap penulis. Penulis harus tetap bisa memperoleh informasi yang otentik berdasarkan kesepakatan dengan para narasumber seperti mitra bisnis, atau teman dekat.

3. Fokus pada peristiwa rutin

Untuk memudahkan penulis memperoleh bahan maka biasanya mereka mencarinya di tempat yang dapat dikunjungi.

4. Menyajikan tulisan yang akrab-informal-manusiawi

Penulis harus menulis secara akrab, tulus ironis, keliru, penuh penilaian dan manusiawi. Namun tetap tanpa opini pribadi. Karena apa yang disajikan kepada pembaca adalah fakta.

5. Gaya penulisan yang sederhana dan memikat

Penulisan sederhana dan memikat diperlukan untuk membuat pembaca tidak hanya melihat tetapi juga merasakan peristiwa.

6. Sudut pandang yang langsung menyapa pembaca. Penulis tidak memposisikan diri secara statis.

7. Menggabungkan narasi primer dan narasi simpangan

Penulis menggabungkan antara kisah utama dengan kisah pendukung yang akan melengkapi laporan. 
Menurut Robert Vare seorang wartawan majalah The New Yorker dan The Rolling Stones, mengatakan ada tujuh pertimbangan bila anda hendak menulis narasi, yaitu:

1. Fakta, jurnalisme menyucikan fakta. Walau pake dasar "sastra" tetapi ia tetap jurnalisme. Setiap detail harus berupa fakta. Nama-nama oarang adalah nama sebenarnya. Tempat juga memang nyata. Kejadian benar-benar kejadian. Merah disebut merah. Hitam hitam. Biru biru. Jurnalisme sastra bukan reportase yang ditulis dengan kata-kata puitis, Narasi boleh puitis tapi tak semua prosa yang puitis adalah narasi.

2. Konflik, sebuah tulisan panjang lebih mudah dipertahankan daya pikatnya bila ada konflik atau sengketa. Sengketa bisa berupa pertikaian satu orang dengan orang lain, ia juga bisa berupa pertikaian antar kelompok, pertentangan seseorang dengan hati nuraninya, bisa berupa pertentengan seseoarang dengan nilai-nilai dimasyarakatnya, dan lain sebagainya. Pendek kata, konflik atau sengketa termasuk unur penting dalam narasi.

3. Karakter, narasi minta ada karakter-karakter. Karakter membantu mengikat cerita. Ada karakter utama dan karakter pembantu. Karakter utama seyogyanya orang yang terlibat dalam pertikaian. Ia harus punya kepribadian menarik. Tak datar dan tak menyerah denga mudah.

4. Akses, bisa berupa wawancara, dokumen, korespondensi, foto, buku harian, gambar, kawan, musuh, dan lain sebagainya.

5. Emosi, ia bisa rasa cinta, pengkhianatan, kebencian, kesetiaan, kekaguman, sikap menjilat dan lain sebagainya.

6. Perjalanan waktu, diibaratkan laporan suratkabar "biasa" dengan sebuah potret. Snap shot. Klik. Klik. Klik. Laporan panjang adalah sebuah film yang berputar. Ia juga membedakan narasi dari feature. Narasi semacam vedeo "series of time" peristiwa berjalan bersama waktu. Sedangkan feature semacam potret sekali jepret. Panjang perjalanan waktu tergantung kebutuhan.

7. Unsur kebaruan, tidak ada gunanya mengulang-ulang lagu lama. Mungkin lebih mudah mengungkapkan kebaruan itu dari kacamata orang biasa yang jadi saksi mata peristiwa besar."

Jika digambarkan, srtuktur penulisan jurnalisme sastra seperti gambar di bawah ini:

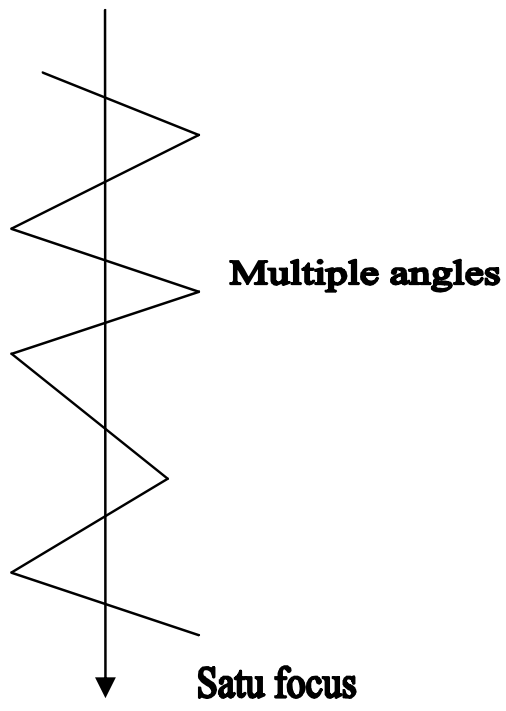

(Sumber: Andreas Harsono, 2009) 


\section{Kategori Feature News}

Friedlander dan Lee memilih beberapa ketegori feature. Ada 14 tipe newspaper feature. Tiap kategori memiliki kekuatan Appeal tertentu dan tiap-tiap kategori membangun topik-topik tertentu,

1. The Bussiness Story

Kisah-kisah human interest diseputar soal bisnis. Pengisahnya biasanya melaporkan bagaimana dunia bisnis penjualan, para pelaku bisnis. Seperti seorang direktur penjualan yang sukses dibeli oleh perusahaan lain dengan harga mahal. Kisah feature melaporkan cara kerja, konsep dan filosofi kerja, sampai kehidupan masa kecil dan keluarganya.

2. The Commemorative Story

Kisah-kisah human interest mengenai perayaan, peringatan, atau nostalgia yang diupacarakan. Dalam hal ini media sering mengkhususkan laporan mengenai peryaan Tahun Baru.

3. The Explanatory Story

Feature yang melaporkan proses kegiatan seperti bagaimana persiapan partai-partai politik menghadapi pelaksanaan pemilihan umum, bagaimana sebuah satsiun radio komersial memprogramkan acara siarannya, bagaimana perajin lokal memproduksi barang yang berkualitas ekspor, dan lain sebagainya.

4. The First-Person Story

Feature yang menceritakan seorang yang menuturkan pengalamannya. Ada peristiwa personal yang ditunggu khalayak. Korban bencana alam nasional yang selamat, pertemuan seseorang dengan tokoh terkenal, dan lain sebagainya.

5. The Historical Story

Feature tentang sejarah. Tempat-tempat bersejarah, kisah di balik peristiwa sejarah, dibalik kehidupan tokoh-tokoh sejarah, dan lain sebagainya.

6. The Hobbyist Story

Feature yang menceritakan tentang kegemaran yang unik dari seseorang. Kisah-kisah kolektor barang-barang antik seperti kolektor mainan kendaraan perang, dan lain sebagainya.

7. The How-To Story

Feature yang menceritakan "how to how-how" bagaimana seseorang atau sesuatu hal memproses sebuah kegiatan. Seperti bagaimana keberhasilan seseorang mencangkok tanaman tertentu hingga tumbuh dan berbuah dalam waktu yang tidak biasa, kisah pengacara yang selalu memenangkan perkaranya, dan lain sebagainya.

8. The Invention Story

Feature yang menceritakan tentang penemuan-penemuan, seperti seorang peneliti menemukan pengobatan dari tetumbuhan atau hewan-hewan atau sesuatu yang tidak terduga, seperti menemukan rakitan teknologi robot, dan lain sebagainya.

9. The Medical Story

Feature yang menceritakan tentang penyakit-penyakit yang diderita oleh manusia yang menyebabkan kematian, seperti penyakit AIDS, kangker, tumor, jantung, dan lain sebagainya.

10. The Odd-Ocuption Story

Feature yang menceritakan seorang pekerja yang memiliki pekerjakan yang unik. Seperti kisah pembersih jendela luar gedung pencakar langit yang menempel di ketinggian puluhan tingkat dikota-kota besar atau kisah seorang penggali kuburm perias jenazah atau pembakar mayat orang yang diabukan, dan lain sebagainya. 


\section{The Overview Story}

Feature yang menceritakan sebuah fenomena aktual di masyarakat, seperti peristiwa kebakaran yang dilaporkan melalui penuturan human interest, problema-problema sosial, dan lain sebagainya.

12. The Participation Story

Kisah-kisah Feature yang dibuat dengan keterlibatan penuh dari penulis. Seperti seorang wartawan tinggal dan hidup berbulan-berbulan di wilayah konflik, mengikuti dan mengamati pertempuran yang terjadi. Laporannya memberi detail-detail yang jarang terungkap pemberitaan reguler.

13. The Profile Story

Feature yang menceritakan profil tokoh-tokoh publik yang tengah jadi pembicaraan. Yaitu menggambarkan potret diri seseorang. Tidak hanya untuk lebih baik lagi penulis profil mengerjakan riset dan wawancara orang-orang yang mengenali tokoh tersebut.

14. The Unfamiliar Visitor Story

Didalam kisah feature ini yaitu mengangkat perspektif orang-orang yang menjadi unfamiliar visitor di masyarakat sehingga khalayak memahami sebuah peristiwa denga lebih bak lagi. Seperti konflik agama dan suku terjadi di wilayah timur Indonesia, orang-orang Ambon atau Maluku (unfamiliar visitor) yang tengah berada di Jakarta diwawancara. Tanggapan, kepedulian, dan kehidupan mereka di laporkan. ${ }^{9}$

\section{Struktur Penulisan Feature}

Kisah penulisan feature berkembang sejak jurnalisme modern diterapkan di Amerika. Pada fase "penny press" di tahun 1830-an. Kisahnya mengadopsi struktur cerita pendek.

Struktur penulisan Feature terbagi kedalam tiga bagian, yaitu: awal (beginnings), tengah (middles), dan akhir (ends). Berbeda dengan kisah berita, feature tidak mengarahkan pembaca. Penulis feature membangun bacaan seutuh mungkin, dalam urutan yang mudah dipahami. Kisahnya tidak bisa dipenggal-penggal. Hanya bisa diedit dengan hati-hati, pada setip bagian dan keseluruhan kisahnya, dari awal sampai akhir kisahnya.

Menurut Daniel R. Williamson (1975: 26) dalam buku Feature Writing for Newspapers, mengatakan "Kunci pembuka kisah feature ada di paragraf pertama, the lead"

Lead menjadi awal pembaca hendak meneruskan bacaannya. Wartawan berusaha keras mengarangsir kata-kata dibagian-bagian ini, agar bisa mengajak pembaca masuk ke dalam pengisahan.

Usai mengatasi lead, penulis feature berhadapan dengan body (tubuh berita) dan ending (penutup). Bila diurut, struktur feature terdiri dari:

1. Judul

Setiap judul memerlukan penanganan yang cermat. Melalui judul, pembaca diajak dan ditarik minat perhatiannya. Dalam feature, judul tidak perlu berupa ringkasan. Yang penting, harus dibuat semenarik mungkin dan dapat menggugah pembaca. Judul feature tidak mesti berkaitan dengan lead. Model ini tidak harus di tulis secara S-P-OK (Subyek-Predikat-Objek-Keterangan). Tidak harus tegas menyiratkan arti. Makna ambigu kerap dibutuhkan bahkan bila perlu imajinatif karena semua ini diperlukan untuk menggugah pembaca.

2. Lead

Lead berguna sebagai pemancing minat dan atensi pembaca. Setiap reporter punya kesadaran tinggi akan perlunya lead. Mereka menghindari lead tidak bermutu dan ituitu saja. Lead pada feature memiliki dua tujuan, pertama, menarik pembaca untuk mengikuti materi tulisan. Kedua, merupakan cara melancarkan pemaparan kisah. Untuk 
dua tujuan itu, lead pun terdiri dari beberapa pilihan dengan kegunaan masing-masing. Ada yang untuk menyentak pembaca, atau menggelitik rasa ingin tahu pembaca, atau merojok imajinasi pembaca, atau meringkas isi feature yang akan dibaca. Tapi, dalam feature, penulis punya banyak keleluasaan dalam memaparkan atau menjelaskan yang ingin diungkapkan. Karena itu, dalam lead, penulis bisa mengombinasi satu-dua jenis lead yang dianggap tepat.

3. Body

Body kisah feature memiliki karakteristik tertentu. Setiap bagiannya bersifat unity (saling menyatu), koheren (saling berhubungan), dan mengundang emphasis (penekanan tertentu) pada tiap paragrapnya.

Ketiga hal itu melancarkan pengisahan. Ketiganya mengarahkan tema pokok laporan, mengemas materi penting, menjembatani perpindahan paragraf dengan enak, mengalir, dan menjauhi kekakuan.

4. ending.

Penutup merupakan bagian akhir dari struktur penulisan feature. Suatu feature memerlukan ending. Ending menjadi penguat tulisan disusun dengan cermat, dan berhubungan dengan keseluruhan laporan. Penutup mendorong akhir kisah menjadi satu kesatuan dengan lead dan Body. ${ }^{10}$

\section{Unsur 5 W + 1 H dalam Lead (Straight News)}

Jurnalisme seringkali disebut "literatur in hurry," kesusastraan yang terburu-buru. Dalam pekerjaan jurnalistik ada unsur ketergesa-gesaan dan kebutuhan akan kecepatan. Itulah sebabnya, sejak munculnya suratkabar sampai sekarang berkembang teknik-teknik penulisan berita yang mengacu pada kecepatan ini, sehingga berita-berita yang ditulis di suratkabar-suratkabar, apalagi di radio dan televisi bentuknya singkat, padat, dan ringkas. ${ }^{11}$

Tetapi, perlu diketahui bahwa tidak ada satu cara pun yang sama yang digunakan suratkabar dalam penulisan beritanya meskipun acuannya masih sama, yaitu kecepatan. Cobalah perhatikan berita-berita yang ditulis suratkabar-suratkabar tentang peristiwa yang sama, maka kita akan mengerti tentang maksud kalimat diatas. Meskipun demikian, jika diperhatikan dengan lebih seksama, maka terilaht bahwa berita-berita di suratkabar umumnya mengikuti sebuah pola, yakni pola piramida terbalik.

Berita dimulai dengan ringkasan atau klimaks dalam alenia pembukanya yang kemudaian dikembangkan lebih lanjut dalam alinea-alinea selanjutnya dengan memaparkan rincian cerita secara kronologis atau dalam urutan yang semakin menurun daya tariknya. Alinea-alinea berikutnya yang memuat rincian berita disebut tubuh berita dan kalimat pembuka yang memuat ringkasan berita yaitu teras berita atau lead.

Rumus $5 \mathrm{~W}+1 \mathrm{H}$ dalam jurnalistik termasuk kedalam unsur-unsur yang lengkap dalam lead. Lead yang baik membutuhkan antara lain selektivitas, yaitu penentuan tentang unsur apa saja yang paling penting. Contoh simpelnya : peristiwa kebakaran (Apa) pengguna kendaraan yang membuang puntung rokok dalam keadaan menyala (Bagaimana) di pom bensin Ciputat Tangerang (Dimana) pengguna kendaraan truk (Siapa) karena api dari puntung rokok yang langsung menyambar bensin (Mengapa) pada siang hari pukul 12:00 WIB (Kapan).

Dari beberapa pemaparan diatas, penulis menyimpulkan bahwa straight news adalah kegiatan menyampaikan berita berupa fakta atau informasi untuk disampaikan kepada khalayak luas dan tidak terlepas dari unsur $5 \mathrm{~W}+1 \mathrm{H}$ dengan struktur penulisan piramida terbalik. Sedangkan feature merupakan berita atau cerita yang dibuat berupa fakta atau informasi semenarik mungkin namun tidak selalu berpedoman pada unsusr $5 \mathrm{~W}+1 \mathrm{H}$. 
Sedangkan Jurnalisme Sastra atau narrative reporting merupakan penulisan berita yang dibuat dalam bentuk narasi dari berbagai sudut pandang yang berbeda sesuai dengan faktafakta yang ada dan bukan karangan fiktif belaka.

\section{Penutup}

Jurnalisme sastra sudah menjadi tren global dalam hal penulisan berita, khususnya di media cetak. Seorang wartawan media cetak harus mampu membuat berita dengan gaya narasi atau jurnalisme sastra, tapi tidaklah mungkin seorang wartawan dengan hasil seminggu mengikuti kursus narasi hanya dengan bekal $5 \mathrm{~W}+1 \mathrm{H}$ bisa memenuhi standar karya Jurnalisme sastra.

Banyak sekali perbedaan yang di buat dalam jurnalisme sastra dengan straight news (berita langsung) maupun feature. Jurnalisme sastra merupakan berita yang ditulis menggunakan gaya narasi yang berkenaan dengan rangkaian peristiwa dengan fakta-fakta yang ada. Tujuannya adalah mengatakan pembaca apa-apa yang terjadi. Selain itu juga struktur penulisannya dibuat dari dua sudut pandang yang berbeda-beda (multiple angles) dan tetap fokus pada struktur penulisan jurnalistik $(5 \mathrm{~W}+1 \mathrm{H})$.

Jurnalisme sastra memberi tempat bagi wartawan di Indonesia untuk mengaktualisasikan keberadaan dirinya. Hal ini karea jurnalisme sastra menuntut wartawan untuk mampu membuat narasi ataupun deksripsi yang rinci, hidup, kontekstual, dan relevan.

\section{Contoh Karya Jurnalisme Sastra}

\section{Cermin Jakarta, Cermin New York}

Jatuh-bangun Majalah The New Yorker

Waktu itu Salatiga hangat dengan macam-macam diskusi politik dan distribusi novel Pramoedya Ananta Toer yang dilarang pemerintah. Mahasiswa mengagumi Arief Budiman, seorang pembangkang dosen Universitas Kristen Satya Wacana, yang melancarkan banyak kritik terhadap kapitalisme dan libralisme, seraya mempromosikan sosialisme. Orang suka bicara politik walau berbisik.

Suatu sore yang tenang, disebuah pondokan di jalan Cemara II, seorang mahasiswa menyodorkan fotokopi majalah berbahasa Inggris yang berisi laporan tentang Soeharto, bisnis anak-anaknya, perseturuan Jenderal Benny Moerdani dan Wakil Presiden Sudharmono, Islam, Timor Timur, dan sebagainya.

Saya kurang perhatikan judulnya. Tapi ada kalimat "A Reporter at Large" yang mencolok. Desain majalahnya agak tak lazim, model majalah kuno pada 1960-an. singkat.

"Berapa ongkos fotokopi ini?" Tanya saya. "Gampang," ujarnya

Malam ini saya baca laporan yang ditulis oleh Raymond Bonner. Laporan dibuka dengan isi dokumen rahasia Rand Corporation -lembaga think tank berpengaruh di Washington DC-beberapa saat setelah Shah Reza Pahlevi dari Iran tersingkir oleh gerakan revolusi Islam. Menurut laporan itu, ada tiga Negara lain yang bisa meniru Iran: Korea Selatan, Filipina, dan Indonesia. Ketiganya dipimpin oleh penguasa otoriter: Chun Doo Hwan, Ferdinand Marcos, serta Soeharto, yang tak segan memanipulasi 
Pemilihan Umum, melakukan pembunuhan politik, korupsi, serta dekat dengan dunia Barat. Pada lapisan menengah dan bawah ada ketakpuasan yang akut terhadap Chun, Marcos, dan Soeharto. Konon saking rahasia, laporan Rand Corporation hanya dicetak 20 eksemplar dan dibagikan ke kalangan terbatas. Presiden Ronald Reagan termasuk satu diantaranya.

Perlahan laporan itu menarik saya masuk ke detail demi detail politik Indonesia. Bonner mengutip professorprofessor Yogyakarta, mahasiswa Bandung, cendikiawan Padang, wartawan Jakarta, dan seorang rektor Makasar. Bagai film kolosal, Bonner menghanyutkan pembaca, pelan-pelan memahami kerumitan sebuah negara yang bernama Indonesia. Bonner tinggal selama dua bulan di Indonesia. Dia membuat janji wawancara di Jakarta, Padang, Makassar, Yogyakarta, Bandung, bahkan Darwin di Australia, ketika dia tak mendapat izin pergi ke Timor Timur. Bonner bicara dengn orang-orang asing yang kenal Indonesia, misalnya Ed Masters dan Marshall Green, keduanya mantan duta besar Amerika di Jakarta. Fredick Bunnel, professor ilmu politik dari Amerika. Jack Whittleton, duta besar kanada di Jakarta. Bonner juga bicara dengan Jose Costa Alves yang menjadi konsul jenderal Portugis di Darwin atau Gubernur Timor Timur Mario Viegas Carrascalao, serta pengusaha "Hotel Turismo" Dili Sebastian Calado. Buat mahasiswa yang suka diskusi, laporan itu menyenangkan karena informasi yang jarang dimuat media massa Jakarta tercetak lengkap, dari fakta, gossip, hingga rasa kecewa, marah, dan kecut. Ibaratnya, saya mengerti politik Jakarta dengan memandang cermin yang diletakkan oleh Bonner. Saya agak lupa berapa lama saya baca laporan Bonner. Semuanya 40 halaman tanpa foto. Tapi seingat saya, semalam saya pakai buat membacanya. Esok hari saya terlambat bangun.

Dalam kantuk, saya perhatikan apa nama majalah yang memberi tempat buat artikel sedahsyat ini. Namanya.... The New Yorker. -Andreas Harsono. $^{12}$

\section{ENDNOTE}

\footnotetext{
${ }^{1}$ Harold D. Lasswell, The Communication of Ideas, (New York: Harper and Bross, 1948), hlm. 48.

${ }^{2}$ Morisan, Jurnalistik Televisi Mutakhir, (Ramdina Prakasa, 2005), hlm. 1 dan 3.

${ }^{3}$ Asep Saeful Muhtadi, hlm. 85.

4 Andreas Harsono dan Budi Setiyono, Jurnalisme Sastra Antologi Liputan Mendalam dan Memikat, (Jakarta: Yayasan Pantau Kebayoran Lama), 2005, hlm. viii.

Sudirman Tebba, Jurnalistik Baru, (Ciputat: Kalam Indonesia Kampung Utan, 2005), hlm. 23-25.

${ }^{6}$ www.semestanet.com, di ambil pada tanggal 25 Maret 2011, pukul 20:00 wib.

${ }^{7}$ www.wordpress.com, Jurnalisme-Sastra-Septiawan-Santana, di ambil pada tanggal tanggal 25 Maret 2011, pukul 20:15 wib.

${ }^{8}$.Andreas Harsono dan Budi Setiyono, Jurnalisme Sastra Antologi Liputan Mendalam dan Memikat, (Jakarta, Yayasan Pantau Kebayoran Lama, 2005), hlm. xii-xv.

${ }^{9}$ Septian Santana K, Jurnalisme Kontemporer, (Jakarta: Yayasan Obor Indonesia, 2005), hlm. 39-41.

${ }^{10}$ Septian Santana K, Jurnalisme Kontemporer, (Jakarta: Yayasan Obor Indonesia, 2005), hlm. 41-47.

${ }^{11}$ Hikmat Kusumaningrat dan Purnama Kusumaningrat, Jurnalistik Teori dan Praktik, (Bandung: PT Remaja Rosdakarya Offset, 2006), hlm. 125.

${ }^{12}$ Andreas Harsono dan Budi Setiyono, Jurnalisme Sastra Antologi Liputan Mendalam dan Memikat, (Jakarta: Yayasan Pantau Kebayoran Lama), 2005, hlm. 307-309.
} 


\section{DAFTAR PUSTAKA}

Harsono, Andreas dan Setiyono, Budi. 2005. Jurnalisme Sastra Antologi Liputan Mendalam dan Memikat. Jakarta: Yayasan Pantau Kebayoran.

Lasswell, Harold D. 1948. The Communication of Idea. New York: Harper and Bross.

Kusumaningrat, Hikmat dan Kusumaningrat, Purnama. 2006. Jurnalistik Teori dan Praktik. Bandung: PT Remaja Rosdakarya Offset.

Morisan. 2005. Jurnalistik Televisi Mutakhir. Ramdina Prakasa.

Santana, Septian K. 2005. Jurnalisme Kontemporer. Jakarta: Yayasan Obor Indonesia.

Tebba, Sudirman. 2005. Jurnalistik Baru. Ciputat: Kalam Indonesia Kampung Utan.

www.semestanet.com, di ambil pada tanggal 25 Maret 2011, pukul 20:00 wib.

www.wordpress.com, Jurnalisme-Sastra-Septiawan-Santana, di ambil pada tanggal tanggal 25 Maret 2011, pukul 20:15 wib. 